\title{
Natural hybridization of Iris species in Mt. Palgong-san, Korea
}

\author{
OGyeong Son, Sung-Won Son ${ }^{1}$, Gang-Uk Suh ${ }^{1}$ and SeonJoo Park* \\ Department of Life Science, Yeungnam University, Gyeongsan 712-749, Korea \\ ${ }^{1}$ Plant Conservation division, Korea National Arboretum, Pochen 487-821, Korea \\ (Received 31 July 2015; Revised 28 August 2015; Accepted 10 September 2015)

\section{팔공산 금붓꽃 계열의 자연 잡종 현상 \\ 손오경 · 손성원 ${ }^{1} \cdot$ 서강욱 ${ }^{1}$ 박선주* \\ 영남대학교 생명과학과, ${ }^{1}$ 국립수목원 산림자원보존과}

\begin{abstract}
Series Chinensis, Genus Iris, endemic to the far regions of East Asia, consists of four species and related varieties. This series is divided into two major groups (I. rossii and I. minutiaurea complex). In this study, the ITS region and matK gene sequences within nuclear ribosomal DNA and plastid DNA were analyzed in order to investigate the phylogenetic relationships among the I. minutiaurea complex (I. minutiaurea, I. odaesanensis, and I. koreana) and the taxonomic identities of a putative hybrid in Mt. Palgong. In the internal transcribed spacer (ITS1, 5.8S, and ITS2) region, a total of 106 cloned genomic sequences from three taxa were obtained to study the intragenomic polymorphisms of the ITS regions. Three taxa revealed high levels of intragenomic polymorphisms, indicative of incomplete nrDNA concerted evolution. This incomplete ITS concerted evolution in the series Chinensis may be linked to the recent species divergence and frequent interspecies hybridization of the series Chinensis. In the matK gene, three taxa were fairly separated by eleven variable sites. In eight individuals collected on Mt. Palgong, putative hybrids between I. odaesanensis and I. minutiaurea were clustered in the I. minutiaurea clade in the NJ (neighbor-joining) tree based on the matK gene. However, in the ITS tree, some of them were clustered in the I. odaesanensis clade and others were clustered in the I. minutiaurea clade. Therefore, the individuals on Mt. Palgong were formed by the hybridization between two taxa ( $I$. odaesanensis and I. minutiaurea) and not through the lineage of I. koreana.
\end{abstract}

Keywords: Iridaceae, Genus Iris, series Chinensis, ITS, matK, polymorphism, hybrid species

적 요: 붓꽃속(Genus Iris)의 금붓꽃계열(Series Chinensis)은 극동아시아에 국한되어 분포하고 있으며 한국에는 총 6분 류군이 자생하고 있다. 이는 크게 두 개의 주요 그룹 (각시붓꽃 complex와 금붓꽃 complex)으로 나뉜다. 본 연구에서는 팔공산에서 발견된 잡종추정개체들의 실체와 붓꽃속 금붓꽃계열 분류군간의 계통학적 유연관계를 규명하기 위해 핵 $\mathrm{rDNA}$ ITS와 엽록체 matK 유전자의 염기서열을 확보하여 분석하였다. 총 55개체로부터 얻은 106 개 ITS amplicon의 염 기서열 및 군외군의 염기서열을 분석한 결과, 금붓꽃계열의 노랑무늬붓꽃, 노랑붓꽃, 금붓꽃 및 잡종추정군은 군외군 과 구분되어 유집되었으나, 군내군 사이에서는 높은 다형성 염기서열이 관측되었다. ITS 계통수에서 잡종추정군의 일 부는 노랑무늬붓꽃과 하나의 분계조를 나타내었고, 나머지 잡종추정군의 경우는 금붓꽃+노랑붓꽃과 분계조를 형성하였 다. 한편 $\mathrm{cpDNA}$ 의 경우 matK를 제외한 나머지 마커는 금붓꽃과 노랑붓꽃의 차이를 보여주지 못하였다. $m a t K$ 의 $\mathrm{NJ}$ 계통 수에서 잡종추정군이 금붓꽃과 높은 Bootstrap 값으로 하나의 분계조를 형성하였으며, 염기서열이 일치하였다. 이 결과 를 바탕으로 팔공산에서 발견된 잡종추정군의 모계는 금붓꽃이고 부계는 노랑무늬붓꽃이라는 가능성을 제시하였다.

주요어: 붓꽃과, 붓꽃속, 금붓꽃계열, ITS, $m a t \mathrm{~K}$, 다형성, 잡종

\footnotetext{
*Author for correspondence: sjpark01@ynu.ac.kr
}

http://www.pltaxa.or.kr

Copyright (C) 2015 the Korean Society of Plant Taxonomists 
붓꽃속(Iris L.)은 APG III분류체계에 의하면 외떡잎식 물군(monocots), 비짜루목(Asparagales) 붓꽃과에 속하는 식물로서 한국, 일본, 시베리아 동부 지역을 중심으로 주 로 북반구 지역에 분포하며 전 세계에 300 여종이 알려져 있다(Yu et al., 2009). 한국산 붓꽃속 식물로는 Palibin (1901)이 처음으로 1속 1종 4변종을 처음 보고한 이후, Nakai (1911, 1914, 1952), Mori (1921), Lee (1976, 1979), Lee (1996) 등에 의해 보고되었다. Sim (1988)은 형태학적인 특 징을 종합 검토하여 한국산 붓꽃속을 4 아속 4절 3아절 7계 열 9종 5 변종 1품종 총 15 분류군으로 정리하였다. 또한 Sim et al. (2002)은 ITS 염기서열 분석을 통해 한국산 붓꽃 속 식물을 3아속(Limniris (Tausch) Spach, Crossiris Spach, Pardanthopsis Hance) 또는 2속과 1아속으로 분류하였으며, $\mathrm{RAPD}$ 분석을 통해 앞선 연구와 비슷한 결론을 제시한바 있다(Sim and Kim, 2002).

붓꽃속 금붓꽃계열(Iris series Chinensis Lawrence)은 식 물체의 크기, 화주, 화피열편 및 종자 등의 형태학적 차이 들에 의해 붓꽃속의 다른 계열과는 뚜렷한 차이를 보이고 있다(Sim and Kim, 2002). 금붓꽃계열에는 8분류군이 주로 극동아시아에 제한적으로 분포하는데(Sim and Kim, 2002), 그 중 우리나라에는 금붓꽃(I. minutoaurea Makino), 노랑붓꽃(I. koreana Nakai), 노랑무늬붓꽃 (I. odaesanensis Y.N. Lee), 각시붓꽃 (I. rossii Baker), 흰각시붓꽃 (I. rossii f. alba Y.N. Lee), 넓은잎각시붓꽃 (I. rossii var. latifolia J.K. $\operatorname{Sim} \&$ Y.S. Kim)의 6 분류군이 자생하고 있으며 이들 각 분 류군들은 각기 독립된 생태적 환경을 가진 집단을 형성하 고 있다. 이 중 금붓꽃 complex의 세 분류군인 금붓꽃, 노 랑붓꽃, 노랑무늬붓꽃은 최근 계통학적 연구결과에 의해 각시붓꽃 complex에 속하는 각시붓꽃, 흰각시붓꽃, 넓은 잎각시붓꽃과는 다른 분화과정을 겪고 있는 것으로 알려 져 있으며(Sim et al, 2002; Sim and Kim, 2002; Lee and Park, 2013), 각각 IUCN에서 제시한 희귀종에 대한 평가기준에 따라 각각 국가단위의 Critically Endangered (노랑붓꽃)와 Vulnerable (노랑무늬붓꽃, 금붓꽃)에 속하는 희귀식물들 이다(Korea National Arboretum, 2008). 또한 한국 특산식물 로 노랑붓꽃, 넓은잎각시붓꽃이 속하고 있어 가치가 있는 식물자원이라 할 수 있다.

노랑붓꽃은 1914년 Nakai (1914)에 의해 전북 정읍에서 처음으로 발견되어 기재된 한국 특산식물이며 과거에는 주로 강원, 경기, 충남, 충북, 경북, 전남, 전북, 제주도 등 전국적으로 분포하는 것으로 되어있으나 $(\mathrm{Oh}, 1986 ; \mathrm{Sim}$, 1992) 최근 분포에 대한 문헌에서는 전북 부안과 전남 담 양, 장성 등 일부 지역에만 제한적으로 분포하고 있다. 노 랑무늬붓꽃은 이(1974)에 의해 오대산에서 처음으로 발견 되어 한국 특산 신분류군으로 등록되었으나 분류군의 계 급에 관해서는 학자들 간에 이견이 있으며 주로 강원도 사명산을 북한계선으로 남쪽의 팔공산까지 주로 태백산 맥을 따라 분포하는 것으로 알려져 있으나(Sim, 1992) 최

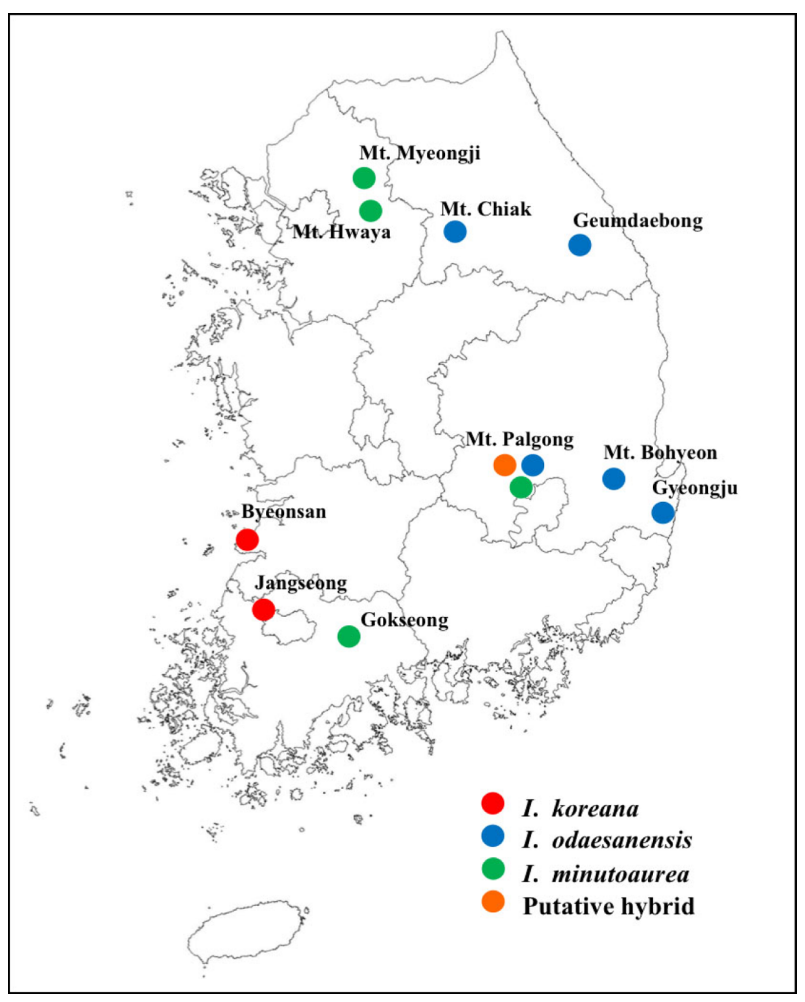

Fig. 1. Map of collecting site.

근에는 중국의 지린성에서도 발견되어(Yutang, 2000) 동아 시아에 널리 분포하는 것으로 보인다. 세 분류군은 외부 형태 형질에서 일정한 차이를 보이고 있는데, 금붓꽃은 화 경 끝에 1 개의 꽃과 2 개의 포를 가지는 데 반해 노랑붓꽃 과 노랑무늬붓꽃은 2 개의 꽃과 3 개의 포를 가지고 있다. 또한 노랑붓꽃은 내외화피편이 모두 황색으로, 외화피편 은 백색이면서 기부에 황색무늬를 가지지만 내화피편은 백색인 노랑무늬붓꽃과 차이를 보인다. 이 외에도 세 분 류군은 자방의 위치에서도 차이를 보이는데, 노랑무늬붓 꽃과 노랑붓꽃은 화피편의 기부에 인접하여 자방이 위치 하고 있는 반면 금붓꽃은 화피편 기부에서 일정 부분 떨 어져서 자방이 위치하고 있다. 이들 각 분류군의 분포양 상 및 서식지 특성을 보면 노랑무늬붓꽃은 한반도의 백두 대간을 따라 산지의 능선이나 계곡 주변에 서식하는 특징 을 보이며, 노랑붓꽃은 주로 전라도 일부 지역의 계곡지 대에서 자생하고 있다. 금붓꽃의 경우는 비교적 전국적 분포를 보이고 있으며 다양한 환경에 자라고 있다. 이들 각 분류군은 일반적으로 생태적 환경이 독립적인 집단을 이루는 것으로 알려져 있으나 본 연구에서 조사된 경북 팔공산 가산지역의 경우는 가산산성을 따라 노랑무늬붓 꽃, 금붓꽃은 독립된 집단을 형성하지 못하고 종간에 혼 합되어 연속적으로 분포하는 양상을 보이고 있다. 이들 집단에서는 자방의 위치, 화피편의 색 등의 형질들에 있 어 중간적인 형태를 보이는 잡종추정개체들이 발견된다. 

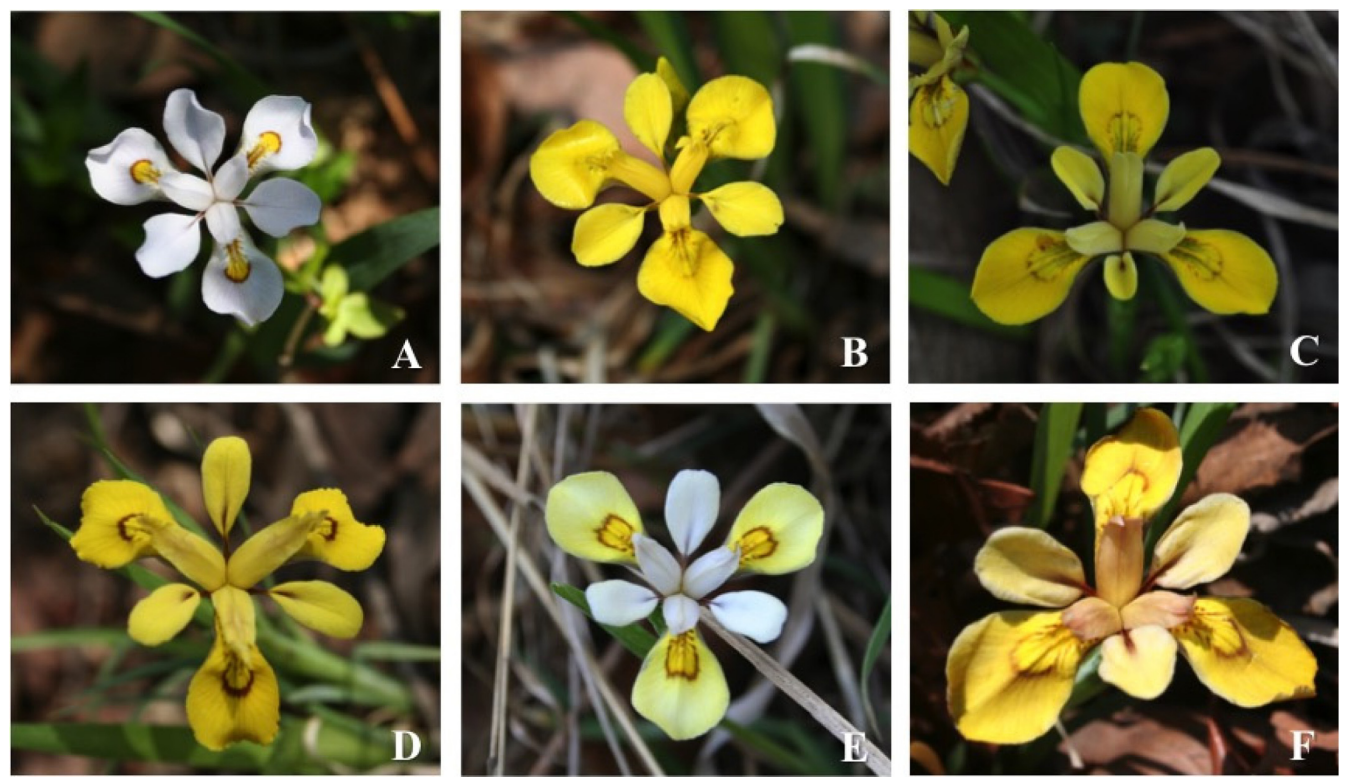

Fig. 2. Flowers of the Iris minutoaurea complex of series Chinensis in Korea. A. I. odaesanensis; B. I. koreana; C. I. minutoaurea; D, E, F. Putative hybrid individuals.

붓꽃속의 종간 잡종현상에 관하여 Arnold et al. (1990)는 서로 인접하여 자생하는 Iris fulva Ker Gawl.와 Iris hexagona Walter 사이의 잡종형성 가능성을 핵 ribosomal DNA 염기서열에서 나타나는 다형성 및 다양성을 통해 제 시한 바 있다. 그 이외에도 Young (1996)은 태평양 연안에 서 혼생하는 Iris douglasiana Herb., Iris innominata L.F.Hend. 그리고 Iris thompsonii R.C.Foster를 대상으로 cpDNA의 마커를 개발하여 분석한 결과 Iris thompsonii는 계통학적으로 독립적인 종을 형성하지 않으며, Iris douglasiana와 Iris innominata 사이의 잡종일 가능성을 주 장한 바 있다.

따라서 본 연구는 한국의 희귀 · 특산식물인 금붓꽃 complex의 세 분류군과 팔공산에서 발견된 잡종추정군을 대상으로 핵 $\mathrm{rDNA} \mathrm{ITS}$ 구간과 엽록체 $\mathrm{DNA}$ 논코딩 구간 (atpF-H, $n d h \mathrm{~F}-r p l 32, p e t \mathrm{~B}-\mathrm{D} \mathrm{IGS}, c l p \mathrm{P}$ 인트론) 및 코딩 구간 $(m a t \mathrm{~K}, r b c \mathrm{~L})$ 염기서열을 결정하고 분석하여, 이들 분류군 사이의 계통유연관계 및 잡종형성 여부를 규명하고자 하 였다.

\section{재료 및 방법}

실험재료: 본 연구에 사용된 재료는 국내 자생하는 금 붓꽃 계열에 속하는 금붓꽃(I. minutoaurea), 노랑붓꽃(I. koreana), 노랑무늬붓꽃(I. odaesanensis), 그리고 팔공산에 서 발견된 잡종추정군 등에서 각각 15 개체, 10 개체, 21 개 체, 10 개체를 확보하여 분석하였다. 채집된 재료는 건조 표본으로 제작하여 국립수목원 식물표본관 $(\mathrm{KH})$ 에 소장 하였다. 군외군(outgroup)으로는 같은 금붓꽃계열에 속하
지만 금붓꽃계열(금붓꽃, 노랑붓꽃, 노랑무늬붓꽃)과는 일정한 유전적 차이를 보이는 각시붓꽃으로 선정하였다 (Sim and Kim, 2002; Lee and Park, 2013).

DNA 추출 및 amplification: 자생지에서 직접 채집한 생 체를 이용하여 Precellys ${ }^{\circledR} 24$ Homogeniser (Bertin Technologies, France)를 이용하여 분쇄시킨 후, Dolye and Doyle (1987)의 CTAB 방법을 수정한 Loockerman and Jansen (1996)의 방법으로 추출하였다. 추출된 DNA는 $1.2 \%$ agarose gel 상에서 전기영동 후, $\mathrm{EtBr}$ 염색법으로 UV 조명아래서 형광 밝기를 상대 비교하고 흡광도를 측정하 여 농도를 확인하였다. ITS 지역의 증폭은 프라이머 ITS4, ITS5 (White et al., 1990)를 이용하였으며, $r b c \mathrm{~L}$ 지역의 증폭 은 프라이머 F1F, F1379R (Wolf et al, 1998), matK지역의 증 폭은 프라이머 matK472F, matK1248R (Yu et al., 2011), $n d h \mathrm{~F}$ 지역의 프라이머는 ndhF1255F (5'-TCC TTC ACG GCG GGA TTA AC-3'), ndhF2092R (5'-TAT GGG AGG TGG GCG AAT CT-3'), atpF-H 지역의 증폭은 프라이머 atpF, atpH (CBOL Plant Working Group, 2009), petB-D지역의 프 라이머는 petB-f, petD-r (Dong et al., 2012), $c l p$ P IGS 지역의 프라이머는 clpP-f, clpP-r (Dong et al., 2012)를 이용하였다. ITS 지역 및 $m a t \mathrm{~K}$ 지역의 증폭을 위한 $\mathrm{PCR}$ 반응용액의 조 성은 주형 DNA $20-50 \mathrm{ng}, 10 \times \operatorname{Diastar}^{\mathrm{TM}} T a q$ DNA 완충액 $2.5 \mu \mathrm{L}, 10 \mathrm{mM}$ 의 dNTPs $0.5 \mu \mathrm{L}, 10 \mathrm{pmol}$ 의 프라이머s 각각 $1 \mu \mathrm{L}, 2.5$ unit의 $\operatorname{Diastar}^{\mathrm{TM}} \mathrm{Taq}$ DNA Polymerase $0.13 \mu \mathrm{L}$ (SolGent Co., Korea)를 첨가 후 마지막으로 전체 부피가 $25 \mu \mathrm{L}$ 가 되도록 하였다. 조제된 반응용액은 ITS 경우 $95^{\circ} \mathrm{C}$ 에서 2 분 동안 최초 denaturation, 이후 $95^{\circ} \mathrm{C}$ 에서 20 초 
Table 1. List of Iris samples used in this study.

\begin{tabular}{|c|c|c|c|c|c|c|}
\hline \multirow{2}{*}{ Taxon } & \multirow{2}{*}{ Abbreviation } & \multirow{2}{*}{ Voucher } & \multirow{2}{*}{ Locality } & \multirow{2}{*}{$\begin{array}{l}\text { No. of } \\
\text { individuals }\end{array}$} & \multicolumn{2}{|c|}{ GenBank accession No. } \\
\hline & & & & & ITS & matK \\
\hline \multirow{15}{*}{$\begin{array}{l}\text { I. minutoaurea } \\
\text { (금붓꽃) }\end{array}$} & PM1 & GPPM1(KH) & \multirow{6}{*}{$\begin{array}{l}\text { Gasan-ri, Gasan-myeon, Chilgok-gun, } \\
\text { Gyeongsangbuk-do (Mt. Palgong) }\end{array}$} & \multirow{6}{*}{6} & KT595386 7 & KT595260 \\
\hline & PM2 & GPPM2(KH) & & & KT595388 9 & KT595261 \\
\hline & PM3 & GPPM3(KH) & & & KT595390 1 & KT595262 \\
\hline & PM4 & GPPM4(KH) & & & KT595392 3 & KT595263 \\
\hline & PM5 & GPPM5(KH) & & & KT595394 5 & KT595264 \\
\hline & PM6 & GPPM6(KH) & & & KT595396 & KT595265 \\
\hline & MM1 & GGMM1(KH) & \multirow{3}{*}{$\begin{array}{l}\text { Jeokmok-ri, Buk-myeon, Gapyeong- } \\
\text { gun, Gyeonggi-do (Mt. Myeongii) }\end{array}$} & \multirow{3}{*}{3} & KT595397 & KT595266 \\
\hline & MM2 & GGMM2(KH) & & & KT595398 9 & KT595267 \\
\hline & MM3 & GGMM3(KH) & & & KT595400 1 & KT595268 \\
\hline & HM1 & GGHM1(KH) & \multirow{3}{*}{$\begin{array}{l}\text { Samhwa-ri, Cheongpyeong-myeon, } \\
\text { Gapyeong-gun, Gyeonggi-do (Mt. } \\
\text { Hwaya) }\end{array}$} & \multirow{3}{*}{3} & KT595402 3 & KT595269 \\
\hline & HM2 & GGHM2(KH) & & & KT595404 5 & KT595270 \\
\hline & HM3 & GGHM3(KH) & & & KT595406 7 & KT595271 \\
\hline & KM1 & JGKM1(KH) & \multirow{3}{*}{$\begin{array}{l}\text { Seonse-ri, Osan-myeon, } \\
\text { Gokseong-gun, Jeollanam-do }\end{array}$} & \multirow{3}{*}{3} & KT595408 9 & KT595272 \\
\hline & KM2 & JGKM2(KH) & & & KT595410 1 & KT595273 \\
\hline & KM3 & JGKM3(KH) & & & KT595412 3 & KT595274 \\
\hline \multirow{9}{*}{$\begin{array}{l}\text { I. koreana } \\
\text { (노랑붓꽃) }\end{array}$} & NK1 & JBNK1(KH) & \multirow{5}{*}{$\begin{array}{r}\text { Seokpo-ri, Jinseo-myeon, } \\
\text { Buan-gun, Jeollabuk-do }\end{array}$} & \multirow{5}{*}{5} & KT595332 3 & KT595275 \\
\hline & NK2 & JBNK2(KH) & & & KT595334 5 & KT595276 \\
\hline & NK3 & JBNK3(KH) & & & KT595336 7 & KT595277 \\
\hline & NK4 & JBNK4(KH) & & & КT595338 9 & KT595278 \\
\hline & NK5 & JBNK5(KH) & & & KT595340 1 & KT595279 \\
\hline & JK1 & JNJK1(KH) & \multirow{4}{*}{$\begin{array}{l}\text { Shinseong-ri, Bukha-myeon, } \\
\text { Jangeong-gun, Jeollabuk-do }\end{array}$} & \multirow{4}{*}{4} & KT595342 & KT595280 \\
\hline & $\mathrm{JK} 2$ & JNJK2(KH) & & & KT595343 & KT595281 \\
\hline & JK3 & JNJK3(KH) & & & KT595344 & KT595282 \\
\hline & JK4 & JNJK4(KH) & & & KT595345 6 & KT595283 \\
\hline \multirow{13}{*}{$\begin{array}{l}\text { I. odaesanensis } \\
\text { (노랑무늬붓꽃) }\end{array}$} & PO1 & GPPO1(KH) & \multirow{9}{*}{$\begin{array}{l}\text { Gasan-ri, Gasan-myeon, Chilgok-gun, } \\
\text { Gyeongsangbuk-do (Mt. Palgong) }\end{array}$} & \multirow{9}{*}{9} & KT595361 3 & KT595288 \\
\hline & $\mathrm{PO} 2$ & GPPO2(KH) & & & KT595364 5 & KT595289 \\
\hline & PO3 & GPPO3(KH) & & & KT595366 8 & KT595290 \\
\hline & $\mathrm{PO} 4$ & GPPO4(KH) & & & KT595369 70 & KT595291 \\
\hline & PO5 & GPPO5(KH) & & & KT595371 3 & KT595292 \\
\hline & PO6 & GPPO6(KH) & & & KT595374 5 & KT595293 \\
\hline & PO7 & GPPO7(KH) & & & KT595376 7 & KT595294 \\
\hline & PO8 & GPPO8(KH) & & & KT595378 9 & KT595295 \\
\hline & PO9 & GPPO9(KH) & & & KT595380 1 & KT595296 \\
\hline & GO1 & GBGO1(KH) & \multirow{2}{*}{$\begin{array}{l}\text { Hwangyong-dong, Gyeongju-si, } \\
\text { Gyeongsangbuk-do }\end{array}$} & \multirow{2}{*}{2} & KT595353 4 & KT595284 \\
\hline & $\mathrm{GO} 2$ & GBGO2(KH) & & & KT595355 6 & KT595285 \\
\hline & BO1 & GYBO1(KH) & \multirow{2}{*}{$\begin{array}{l}\text { Jeonggak-ri, Hwabuk-myeon, } \\
\text { Yeongcheon-si, Gyeongsangbuk-do } \\
\text { (Mt. Bohyeon) }\end{array}$} & & KT595357 8 & KT595286 \\
\hline & $\mathrm{BO} 2$ & GYBO2(KH) & & 2 & KT595359 60 & KT595287 \\
\hline
\end{tabular}


Table 1. Continued.

\begin{tabular}{|c|c|c|c|c|c|c|}
\hline \multirow{6}{*}{$\begin{array}{l}\text { I. odaesanensis } \\
\text { (노랑무늬붓꽃) }\end{array}$} & $\mathrm{CO} 1$ & GWCO1(KH) & \multirow{3}{*}{$\begin{array}{l}\text { Hakgok-ri, Socho-myeon, Wonju-si, } \\
\text { Gangwon-do (Mt. Chiak) }\end{array}$} & \multirow{3}{*}{3} & KT595347 8 & KT595297 \\
\hline & $\mathrm{CO} 2$ & GWCO2(KH) & & & KT595349 50 & KT595298 \\
\hline & $\mathrm{CO} 3$ & GWCO3(KH) & & & KT595351 2 & KT595299 \\
\hline & KO1 & GGKO1(KH) & \multirow{3}{*}{$\begin{array}{l}\text { Gohan-ri, Gohan-eup, Jeongseon-gun, } \\
\text { Gangwon-do }\end{array}$} & \multirow{3}{*}{3} & KT595382 & KT595300 \\
\hline & $\mathrm{KO} 2$ & GGKO2(KH) & & & KT595383 & KT595301 \\
\hline & $\mathrm{KO} 3$ & GGKO3(KH) & & & KT595384 5 & KT595302 \\
\hline \multirow[t]{8}{*}{ Putative hybrid } & SP1 & GPSP1(KH) & \multirow{8}{*}{$\begin{array}{l}\text { Gasan-ri, Gasan-myeon, Chilgok-gun, } \\
\text { Gyeongsangbuk-do (Mt. Palgong) }\end{array}$} & \multirow{8}{*}{8} & KT595308 12 & KT595252 \\
\hline & SP2 & GPSP2(KH) & & & KT595313 4 & KT595253 \\
\hline & SP3 & GPSP3(KH) & & & KT595315 9 & KT595254 \\
\hline & SP4 & GPSP4(KH) & & & KT595320 2 & KT5952595 \\
\hline & SP5 & GPSP5(KH) & & & KT595323 5 & KT5952596 \\
\hline & SP6 & GPSP6(KH) & & & KT595326 7 & KT595257 \\
\hline & SP7 & GPSP7(KH) & & & КТ595328 9 & KT595258 \\
\hline & SP8 & GPSP8(KH) & & & KT595330 1 & KT595259 \\
\hline \multirow{2}{*}{$\begin{array}{l}\text { I. rossii var. latifolia } \\
\text { (넓은잎각시붓꽃) }\end{array}$} & \multirow{2}{*}{ IRL } & 889 (MWU) & Daejon, Anyeong-ri & 1 & KT595306 & - \\
\hline & & $63126(\mathrm{KH})$ & Chungcheongnam-do, Gongju-si & 1 & - & KT595303 \\
\hline $\begin{array}{l}\text { I. rossii f. alba } \\
\text { (흰각시붓꽃) }\end{array}$ & IRF & 870 (MWU) & Jeollanam-do, Mt. Jogyesan & 1 & KT595304 & - \\
\hline \multirow{4}{*}{$\begin{array}{l}\text { I. rossii } \\
\text { (각시붓꽃) }\end{array}$} & IR1 & 887 (MWU) & Daejon, Okyebong & 1 & KT595305 & - \\
\hline & IR2 & 027(YNUH) & Gyeongsangbuk-do, Seongju-gun & 1 & KT595307 & - \\
\hline & IR1 & $\mathrm{Z} 260$ & \multirow[t]{2}{*}{-} & \multirow{2}{*}{2} & - & JF954165 \\
\hline & IR2 & Z111 & & & - & JF954166 \\
\hline
\end{tabular}

denaturation, $56^{\circ} \mathrm{C}$ 에서 40 초 annealing, $72^{\circ} \mathrm{C}$ 에서 1 분 extension으로 구성된 반응을 35회 반복한 후, 최종적으로 $72^{\circ} \mathrm{C}$ 에서 5 분간 extension 하였다. cpDNA의 경우 annealing 온도를 $r b c \mathrm{~L} 52^{\circ} \mathrm{C}, \operatorname{mat} \mathrm{K} 48^{\circ} \mathrm{C}, n d h \mathrm{~F} 55^{\circ} \mathrm{C}, a t p \mathrm{~F}-\mathrm{H} 50^{\circ} \mathrm{C}$, petB$\mathrm{D} 52^{\circ} \mathrm{C}, \operatorname{clpP} 52^{\circ} \mathrm{C}$ 에서 40 초, $72^{\circ} \mathrm{C}$ 에서 1 분 extension 으로 구 성된 반응을 35 회 반복한 후 최종적으로 $72^{\circ} \mathrm{C}$ 에서 5 분간 extension 하였다. PCR 반응액은 $\mathrm{Solg}^{\mathrm{TM}} \mathrm{Gel} \& \mathrm{PCR}$ purification system kit (Solent Co., Korea)로 정제하였다. 염 기서열 분석은 automatic DNA analyzer system ABI PRISM 3730xl analyzer (Solent Co., Korea)를 이용하였다.

한편 $m a t \mathrm{~K}$ 지역 이외의 논코딩 지역 $(a t p \mathrm{~F}-\mathrm{H}$, petB-D IGS, $c l p \mathrm{P}$ 인트론)과 코딩지역의 $n d h \mathrm{~F}, r b c \mathrm{~L}$ 지역의 경우 노랑붓 꽃과 금붓꽃의 염기서열이 차이가 없어 제시하지 않았다.

클로닝: nrDNA의 ITS의 경우 대부분 다형(polymorphic) 염기서열이 관찰되어 클로닝을 수행하였다. 클로닝에는 T-Blunt vector (Solgent, $\mathrm{Co}$ )를 이용하였다. 증폭된 PCR 산 물 $4,6 \times$ T-Blunt vector $1 \mu \mathrm{L}$, T-Blunt vector 1 를 넣고 섞은 후 상온에서 5 분 동안 반응 시킨 후, ligation 반응물 $6 \mu \mathrm{L}$ 를 competent cell에 넣어 얼음에서 30 분간 반응하였다. 그 다 음 $42^{\circ} \mathrm{C}$ 에서 30 초간 heat shock을 주고 바로 얼음에 2 분간
안정화하였다. 실온으로 예열된 S.O.C. 배지를 $900 \mu \mathrm{L}$ 를 첨가한 후 shaking incubator에서 1시간동안 $37^{\circ} \mathrm{C}$ 로 배양하 였다. 배양된 반응물을 $200 \mu \mathrm{L}$ 를 X-gal $20 \mu \mathrm{L}$, IPTG $20 \mu \mathrm{L}$ 와 함께 $\mathrm{LB} / \mathrm{ampicillin}$ plates에 도말하고 $37^{\circ} \mathrm{C}$ 에서 20 시간 배양하였다. 이 후 각 plate에서 무작위로 1-5개의 백색 콜 로니를 채취하여 ITS 4, ITS 5 프라이머를 이용하여 PCR 하여 총 106 개의 ITS 클론 염기서열을 얻었다. 이후 $\mathrm{GEL}$ \& PCR Purification System (Solgent Co.)을 이용하여 정제 후 염기서열을 분석하였다.

염기서열 정렬 및 계통분석: 계통학적 분석으로 얻어 진 각 염기서열의 정렬은 Geneious pro v6.1 (Drummond et $\mathrm{al}, .2011)$ 를 이용하였으며, 정렬 결과 발생한 gap은 결여 형질로 처리하고 전체 형질에 있어 가중치는 동일하게 처리하였다. 정렬된 염기서열은 PAUP* ver $4.0 \mathrm{~b} 10$ (Swofford, 2003)을 이용하여 염기서열간의 유전적 거리 (Kimura two-parameter methods; Kimura, 1980)에 기초한 Neighbor-joining (NJ) 계통수를 제작하였다(Saitou and Nei, 1987; Farris et al., 1996). 또한 각 계통수의 지지정도 를 알아보기 위하여 Bootstrap (Felsenstain, 1985)을 수행 하였다. 


\section{결 과}

\section{금붓꽃 complex 내의 염기서열변이 및 특성}

증폭하여 얻은 ITS 지역을 정렬하여 분석한 전체 구간 의 길이는 $663 \mathrm{bp}$ 로 나타났다. 하지만 군외군을 제외한 금 붓꽃 compelx 세 분류군 55 개체 106 개의 amplicons의 ITS 염기서열을 확인한 결과 88 가지의 ribotype을 확인하였다. 각 분류군의 경우 노랑붓꽃에서 14 개의 ribotype, 노랑무 늬붓꽃에서 27 개의 ribotype, 금붓꽃에서 25 개의 ribotype 을 확인하였으며, 잡종추정군에서는 22 개의 ribotype을 확 인하였다. $\mathrm{G}+\mathrm{C}$ 함량의 빈도는 각 종별 노랑무늬붓꽃 $64.4 \%$, 노랑붓꽃 $63.5 \%$, 금붓꽃 $61.3 \%$, 잡종추정군은 $65.2 \%$ 로 나타났다(Table 2).

증폭하여 얻은 $\mathrm{cpDNA}$ 인 $m a t \mathrm{~K}$ 지역을 정렬하여 분석한 결과, 전체 구간의 길이는 잡종추정군을 포함한 금붓꽃 complex 세 분류군 모두 $751 \mathrm{bp}$ 로 나타났다. 분석된 염기
서열의 $\mathrm{G}+\mathrm{C}(\%)$ 염기조성은 잡종추정군 $31.8 \%$, 금붓꽃 $31.8 \%$, 노랑붓꽃 $32.0 \%$, 노랑무늬붓꽃 $31.2 \%$ 로 계산되었 다. 염기서열 중 20 개의 site에서 변이를 보였다(Table 3). 노랑무늬붓꽃의 경우 2 개 site $(232 \mathrm{bp}, 663 \mathrm{bp})$ 가 고유파생 형질(autapomorphy)이었는데, 경북(보현산, 팔공산, 경주) 의 개체군들은 $421 \mathrm{bp}$ 에서 다른 개체군들과 차이를 나타 냈다. 금붓꽃과 노랑붓꽃은 대부분 염기서열의 차이가 없 었으나 하나의 site $(408 \mathrm{bp})$ 에서 금붓꽃의 고유파생형질 이 발견됨으로써 두 분류군의 구별이 가능하였다. 잡종추 정군의 경우 금붓꽃의 염기서열과 동일한 염기서열을 보 였다(Table 3).

\section{분자계통학적 분석}

팔공산에서 발견한 잡종추정군의 계통학적 위치와 자 연잡종을 밝히기 위해 금붓꽃 계열의 6 종 55 개체 106 개의 amplicon을 포함하여 NJ 계통수를 얻었으며, BS (bootstrap

Table 2. Characteristics of nrITS region in Iris minutoaurea complex in Korea.

\begin{tabular}{lcccc}
\hline \hline & I. odaesanensis & I. koreana & I. minutoaurea & Putative hybrid \\
\hline Number of individuals & 19 & 9 & 15 & 8 \\
Cloned genomic sequences & 39 & 15 & 28 & 24 \\
Ribotype & 27 & 14 & 25 & 22 \\
Length variation(Min.-Max.) & $632-637$ & $615-641$ & $601-641$ & $632-640$ \\
G+C (\%) & 64.4 & 63.5 & 61.3 & 65.2 \\
\hline
\end{tabular}

Table 3. DNA sequence variation of matK among Iris minutoaurea complex in Korea.

\begin{tabular}{|c|c|c|c|c|c|c|c|c|c|c|c|c|c|c|c|c|c|c|c|c|c|}
\hline \multirow{3}{*}{ Taxon } & \multirow{3}{*}{ Abbreviation } & \multicolumn{20}{|c|}{ Variable nucleotide sites in alignment } \\
\hline & & \multicolumn{20}{|c|}{ matK } \\
\hline & & 3 & 26 & 65 & 121 & 165 & 213 & 232 & 314 & 349 & 354 & 363 & 381 & 408 & 413 & 421 & 598 & 603 & 663 & 664 & 668 \\
\hline Putative hybrid & SP & $\mathrm{T}$ & $\mathrm{G}$ & $\mathrm{C}$ & $\mathrm{T}$ & $\mathrm{C}$ & G & $\mathrm{C}$ & $\mathrm{C}$ & A & $\mathrm{T}$ & G & G & $\mathrm{T}$ & $\mathrm{A}$ & G & A & G & $\mathrm{C}$ & G & $\mathrm{T}$ \\
\hline \multirow{4}{*}{$\begin{array}{l}\text { I. minutoaurea } \\
\text { (금붓꽃) }\end{array}$} & PM & $\mathrm{T}$ & $\mathrm{G}$ & $\mathrm{C}$ & $\mathrm{T}$ & $\mathrm{C}$ & G & $\mathrm{C}$ & $\mathrm{C}$ & A & $\mathrm{T}$ & G & G & $\mathrm{T}$ & A & G & A & G & $\mathrm{C}$ & G & $\mathrm{T}$ \\
\hline & MM & $\mathrm{T}$ & G & $\mathrm{C}$ & $\mathrm{T}$ & $\mathrm{C}$ & G & $\mathrm{C}$ & $\mathrm{C}$ & A & $\mathrm{T}$ & G & G & $\mathrm{T}$ & A & G & A & G & $\mathrm{C}$ & G & $\mathrm{T}$ \\
\hline & HM & $\mathrm{T}$ & G & $\mathrm{C}$ & $\mathrm{T}$ & $\mathrm{C}$ & $\mathrm{G}$ & $\mathrm{C}$ & $\mathrm{C}$ & A & $\mathrm{T}$ & $\mathrm{G}$ & $\mathrm{G}$ & $\mathrm{T}$ & A & $\mathrm{G}$ & A & G & $\mathrm{C}$ & $\mathrm{G}$ & $\mathrm{T}$ \\
\hline & $\mathrm{KM}$ & $\mathrm{T}$ & $\mathrm{G}$ & $\mathrm{C}$ & $\mathrm{T}$ & $\mathrm{C}$ & G & $\mathrm{C}$ & $\mathrm{C}$ & A & $\mathrm{T}$ & $\mathrm{G}$ & $\mathrm{G}$ & $\mathrm{T}$ & A & $\mathrm{G}$ & A & G & $\mathrm{C}$ & $\mathrm{G}$ & $\mathrm{T}$ \\
\hline \multirow{2}{*}{$\begin{array}{l}\text { I. koreana } \\
\text { (노랑붓꽃) }\end{array}$} & NK & $\mathrm{T}$ & $\mathrm{G}$ & $\mathrm{C}$ & $\mathrm{T}$ & $\mathrm{C}$ & $\mathrm{G}$ & $\mathrm{C}$ & $\mathrm{C}$ & A & $\mathrm{T}$ & G & $\mathrm{G}$ & $\mathrm{G}$ & A & $\mathrm{G}$ & A & G & $\mathrm{C}$ & $\mathrm{G}$ & $\mathrm{T}$ \\
\hline & JK & $\mathrm{T}$ & $\mathrm{G}$ & $\mathrm{C}$ & $\mathrm{T}$ & $\mathrm{C}$ & $\mathrm{G}$ & $\mathrm{C}$ & $\mathrm{C}$ & A & $\mathrm{T}$ & $\mathrm{G}$ & G & $\mathrm{G}$ & A & G & A & $\mathrm{G}$ & $\mathrm{C}$ & $\mathrm{G}$ & $\mathrm{T}$ \\
\hline \multirow{5}{*}{$\begin{array}{l}\text { I. odaesanensis } \\
\text { (노랑무늬붓꽃) }\end{array}$} & $\mathrm{PO}$ & $\mathrm{T}$ & $\mathrm{G}$ & $\mathrm{C}$ & $\mathrm{T}$ & A & A & A & $\mathrm{T}$ & $\mathrm{C}$ & $\mathrm{T}$ & A & $\mathrm{G}$ & $\mathrm{G}$ & A & A & A & $\mathrm{T}$ & $\mathrm{T}$ & $\mathrm{G}$ & $\mathrm{C}$ \\
\hline & $\mathrm{GO}$ & $\mathrm{T}$ & $\mathrm{G}$ & $\mathrm{C}$ & $\mathrm{T}$ & A & A & A & $\mathrm{T}$ & $\mathrm{C}$ & $\mathrm{T}$ & A & G & $\mathrm{G}$ & A & A & A & $\mathrm{T}$ & $\mathrm{T}$ & G & $\mathrm{C}$ \\
\hline & $\mathrm{BO}$ & $\mathrm{T}$ & $\mathrm{G}$ & $\mathrm{C}$ & $\mathrm{T}$ & A & A & A & $\mathrm{T}$ & $\mathrm{C}$ & $\mathrm{T}$ & A & $\mathrm{G}$ & $\mathrm{G}$ & A & A & A & $\mathrm{T}$ & $\mathrm{T}$ & $\mathrm{G}$ & $\mathrm{C}$ \\
\hline & $\mathrm{CO}$ & $\mathrm{T}$ & $\mathrm{G}$ & $\mathrm{C}$ & $\mathrm{T}$ & A & A & A & $\mathrm{T}$ & $\mathrm{C}$ & $\mathrm{T}$ & A & $\mathrm{G}$ & $\mathrm{G}$ & A & $\mathrm{G}$ & A & $\mathrm{T}$ & $\mathrm{T}$ & $\mathrm{G}$ & $\mathrm{C}$ \\
\hline & $\mathrm{KO}$ & $\mathrm{T}$ & $\mathrm{G}$ & $\mathrm{C}$ & $\mathrm{T}$ & A & A & A & $\mathrm{T}$ & $\mathrm{C}$ & $\mathrm{T}$ & A & $\mathrm{G}$ & $\mathrm{G}$ & A & G & A & $\mathrm{T}$ & $\mathrm{T}$ & $\mathrm{G}$ & $\mathrm{C}$ \\
\hline \multirow{2}{*}{$\begin{array}{l}\text { I. rossi } \\
\text { (각시붓꽃) }\end{array}$} & IR1 & $\mathrm{T}$ & $\mathrm{G}$ & $\mathrm{T}$ & $\mathrm{C}$ & A & A & $\mathrm{C}$ & $\mathrm{T}$ & $\mathrm{C}$ & $\mathrm{T}$ & A & A & G & A & G & $\mathrm{C}$ & $\mathrm{T}$ & $\mathrm{C}$ & A & $\mathrm{C}$ \\
\hline & IR2 & $\mathrm{T}$ & $\mathrm{G}$ & $\mathrm{T}$ & $\mathrm{C}$ & A & A & $\mathrm{C}$ & $\mathrm{T}$ & $\mathrm{C}$ & $\mathrm{T}$ & A & A & $\mathrm{G}$ & A & $\mathrm{G}$ & $\mathrm{C}$ & $\mathrm{T}$ & $\mathrm{C}$ & A & $\mathrm{C}$ \\
\hline $\begin{array}{l}\text { I. rossi var. latiflora } \\
\text { (넓은잎각시붓꽃) }\end{array}$ & $\mathrm{NG}$ & G & A & $\mathrm{C}$ & $\mathrm{C}$ & A & $\mathrm{A}$ & $\mathrm{C}$ & $\mathrm{T}$ & $\mathrm{C}$ & $\mathrm{C}$ & A & $\mathrm{G}$ & $\mathrm{G}$ & $\mathrm{C}$ & $\mathrm{G}$ & $\mathrm{C}$ & $\mathrm{T}$ & $\mathrm{C}$ & A & C \\
\hline
\end{tabular}




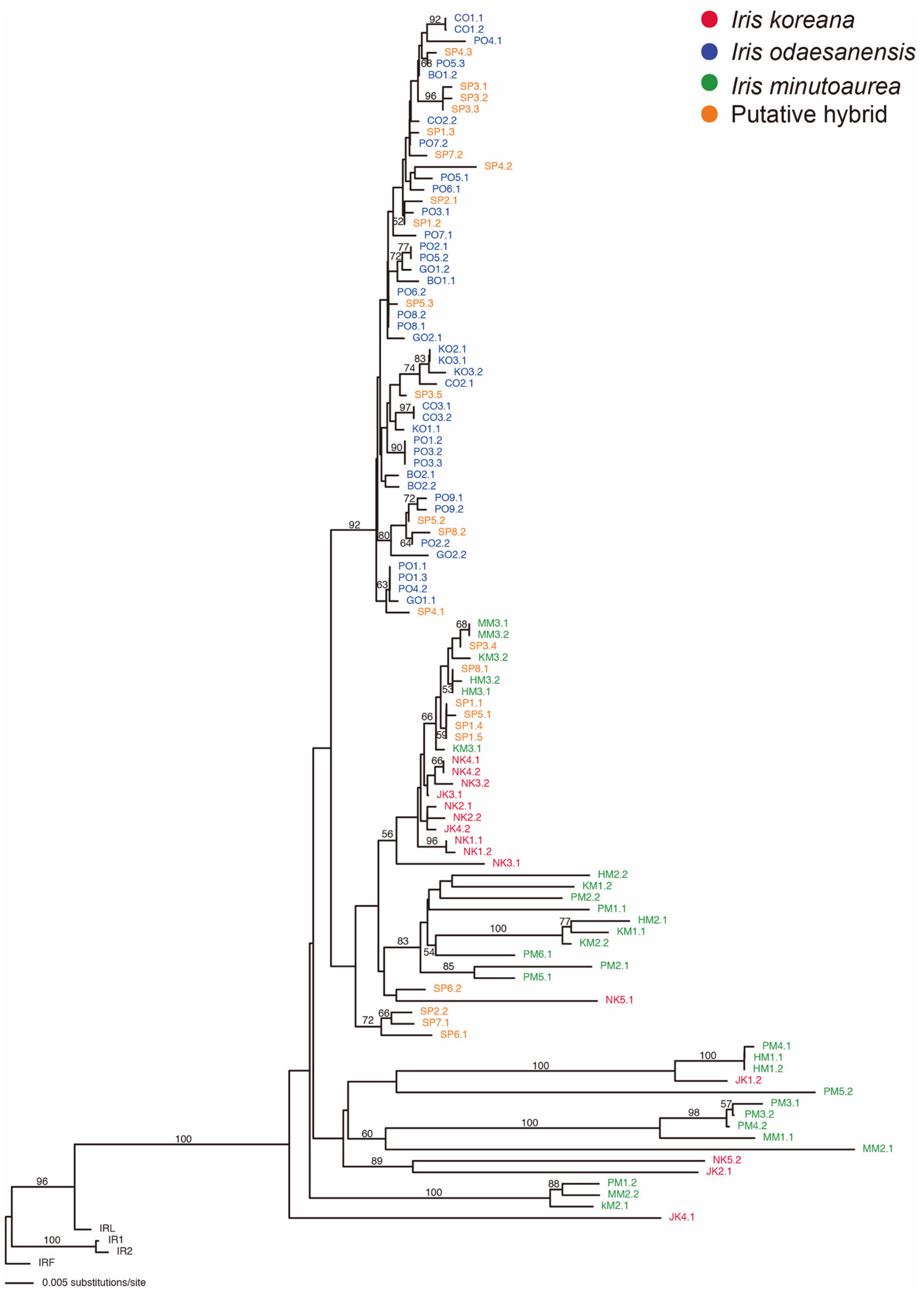

Fig. 3. Neighbor-joinging tree of Iris minutoaurea complex in Korea based on the ITS sequence. The bootstrap values (>50\%) are shown above or below branches. Refer Table 1 for OTU abbreviations. 
value)의 경우 값이 $50 \%$ 이상인 분계조(clade)에 한하여 계 통수에 표시하였다. $\mathrm{NJ}$ 분석 결과 군외군을 제외한 금붓 꽃 complex는 $100 \%$ 의 $\mathrm{BS}$ 로 강한 지지를 받으며 하나의 분 계조를 형성하였다. 노랑무늬붓꽃은 $92 \%$ 의 $\mathrm{BS}$ 값으로 금 붓꽃 complex내에서 단일 분계조로 묶이며 단게통을 이루 었으나, 노랑붓꽃과 금붓꽃의 경우 낮은 $\mathrm{BS}$ 값을 보이며 분계조를 형성하지 못하였다. 팔공산 잡종추정군의 14 개 amplicon은 노랑무늬붓꽃의 분계조와 자매군을 형성하였 고, 그 외 9개의 amplicon은 금붓꽃과 분계조를 형성하거 나 노랑무늬붓꽃과 분계조를 형성하며 $\mathrm{NJ}$ 계통수 전반에 분포하는 양상을 보였다(Fig. 3).

또한 $m a t \mathrm{~K}$ 지역을 분석하여 얻은 $\mathrm{NJ}$ 계통수에서 군외 군을 제외한 금붓꽃 complex가 $96 \%$ 의 BS값으로 하나의 분계조를 나타내었다. 군외군을 제외한 금붓꽃 complex
내 종간 유연관계로는 크게 노랑무늬붓꽃과 금붓꽃+노랑 붓꽃+잡종추정군의 2 개의 분계조로 나뉘어졌다. 노랑무 늬붓꽃 분계조는 $84 \%$ 의 $\mathrm{BS}$ 로 높은 지지를 받으며 하나의 분계조를 형성하였으며 군외군인 넓은잎각시붓꽃과 각 시붓꽃은 노랑무늬붓꽃과 가까운 유연관계를 보였다. 노 랑붓꽃+금붓꽃+잡종추정군은 $100 \%$ 의 $\mathrm{BS}$ 값으로 가까운 유연관계를 보여주고 있음을 확인하였다. 노랑무늬붓꽃 개채군내에서는 하나의 염기서열의 차이로 경상북도에 분포하는 팔공산, 보현산, 경주집단과 강원도에 분포하는 금대봉, 치악산 집단 또한 하나의 분계조를 형성하였다. 노랑붓꽃 + 금붓꽃 + 잡종추정군 또한 하나의 분계조를 형 성하였으나, 노랑붓꽃과 금붓꽃+잡종추정군은 자매군을 형성하였다. 금붓꽃과 잡종추정군은 $100 \%$ 의 $\mathrm{BS}$ 로 하나 의 분계조를 형성하였다(Fig. 4).

\section{- Iris koreana \\ - Iris odaesanensis \\ - Iris minutoaurea \\ Putative hybrid}

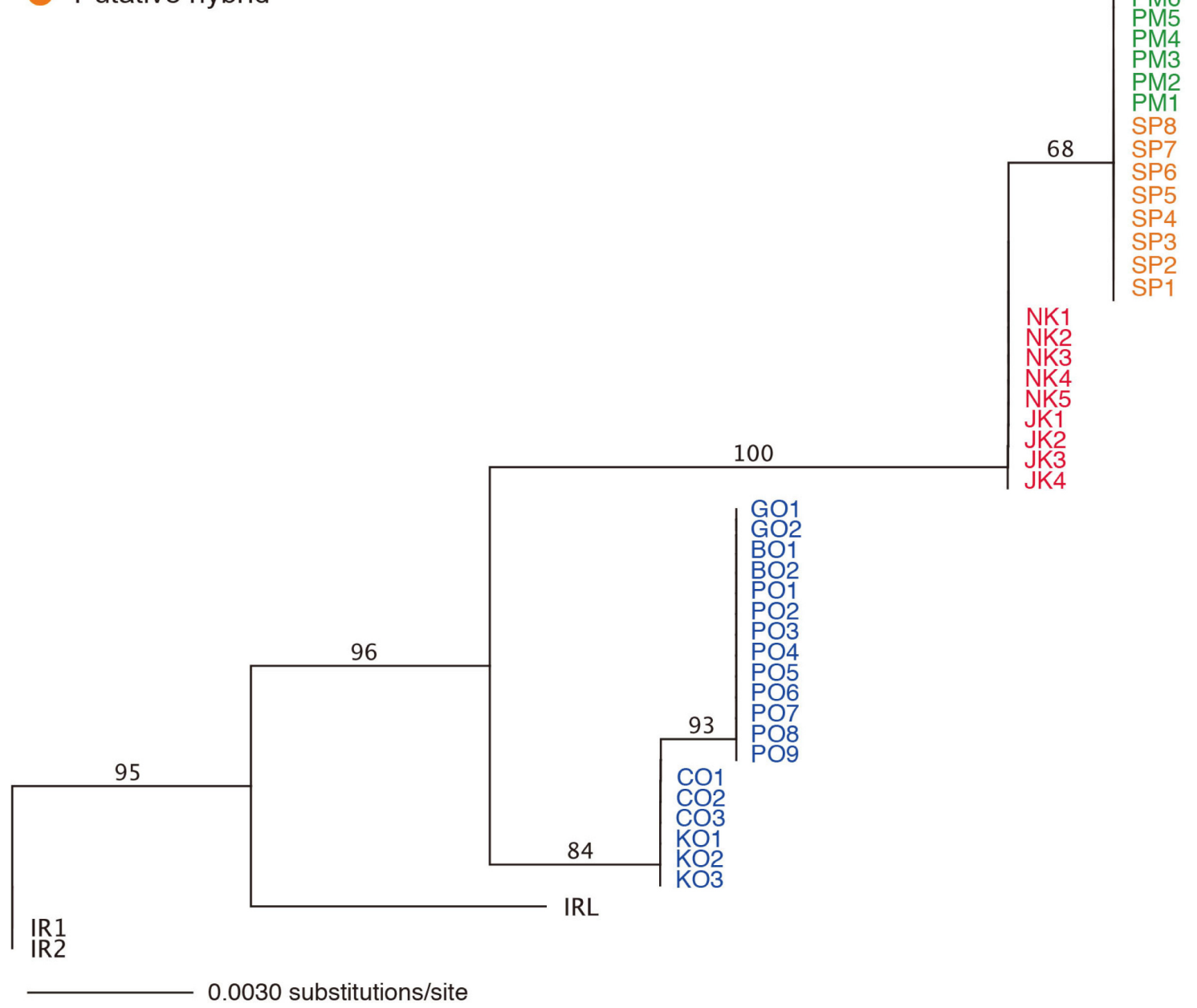

Fig. 4. Neighbor-joinging tree of Iris minutoaurea complex in Korea based on the matK gene sequence. Refer Table 1 for OTU abbreviations. 


\section{고 찰}

본 논문에서는 한국산 금붓꽃 complex에 속하는 세 분 류군과 팔공산에서 발견한 잡종추정군을 포함한 4분류군 에 대해서 $\mathrm{nrDNA}$ ITS지역과 cpDNA에 속하는 코딩지역 $m a t \mathrm{~K}, r b c \mathrm{~L}, n d h \mathrm{~F}$ 와 논코딩 지역 $a t p \mathrm{~F}-\mathrm{H}, p e t \mathrm{~B}-\mathrm{D}$ IGS, $c l p \mathrm{P}$ 인트론의 염기서열을 이용한 분자계통학적 연구를 수행 하여 잡종추정군의 자연잡종의 가능성 및 분류군간의 유 연관계를 파악하고자 하였다.

먼저 팔공산 잡종추정군의 분류학적 위치를 명확히 파 악하기 위해서 세 분류군간의 유연관계에 관한 선행연구 를 진행하였다. ITS 계통수에서 노랑무늬붓꽃은 높은 BS 값으로 지지받으며 완벽한 하나의 분계조를 형성하였다. 이는 노랑무늬붓꽃을 노랑붓꽃의 변종(Lee, 1984) 또는 품 종(Lee and Lee, 1964)으로 처리하기 보다는 독립된 종으로 간주할 것을 제시한 Lee (1996), Sim (1988), Lee and Park (2013)의 견해를 지지한다. 노랑붓꽃의 경우 화경 끝에 2 개의 꽃이 달리는 점과 자방이 돌출되는 특징으로 금붓꽃 과 뚜렷이 구분되지만, ITS 계통수에서는 이 두 종이 각기 다른 분계조로 묶이지 않아 종간 구분이 불가능하였다. 이는 노랑붓꽃과 금붓꽃이 최근에 분화되었거나 혹은 복 잡한 진화를 격었기 때문으로 생각되며, 두 종의 한계 혹 은 종내 개체간의 관계를 밝히기 위해서는 single 또는 low copy nuclear gene을 이용한 연구가 필요할 것으로 사료된 다. cpDNA의 $m a t \mathrm{~K}$ 지역을 제외한 모든 지역 $(r b c \mathrm{~L}, n d h \mathrm{~F}$, $a t p \mathrm{~F}-\mathrm{H}, p e t \mathrm{~B}-\mathrm{D}$ IGS, $c l p \mathrm{P}$ 인트론)의 염기서열을 분석한 결 과, 금붓꽃 complex의 세 분류군 중 노랑무늬붓꽃과 노랑 붓꽃+금붓꽃의 염기서열의 차이는 지속적으로 보이나 노 랑붓꽃과 금붓꽃의 염기서열은 차이가 보이지 않아 세 분 류군간의 유연관계 파악에 활용할 수 없었다. 이는 최근 에 발표한 Lee and Park (2013)의 cpDNA의 $p s b \mathrm{~A}-\mathrm{trn \textrm {H }}$, $t r n \mathrm{~L}-$ $\mathrm{F}$ 의 계통분류학적 연구결과 금붓꽃과 노랑붓꽃 두 종의 관계가 모호하다는 결과와 일치한다. 한편 $m a t \mathrm{~K}$ 의 분석 결과에서는 비록 금붓꽃과 노랑붓꽃 사이에 하나의 염기 서열 차이만 보였지만 금붓꽃 complex의 세 분류군의 명 확한 염기서열의 차이가 확인되었다. 따라서 $\mathrm{cpDNA}$ 의 $m a t \mathrm{~K}$ 계통수는 금붓꽃 complex의 분류학적 문제점을 해 결하고 정확한 종분류와 분류군간의 유연관계를 검토하 는 데 매우 유용한 것으로 사료된다.

팔공산에 분포하는 잡종추정군은 금붓꽃과 노랑무늬 붓꽃이 혼생하며 나타나는 지역에서 발견하였으며, 형태 학적으로 금붓꽃과 노랑무늬붓꽃의 연속적인 변이의 형 태를 보이고 있었다. Iris속은 Arnold et al. (1990)과 Young (1996)에 의하여 자연적인 종간 잡종가능성에 대하여 밝 혀진 바 있다. 형태적으로 여러 변이를 보이는 잡종추정 군의 분류학적 위치를 알아내기 위하여, 먼저 모계유전을 하는 $\mathrm{cpDNA}$ 마커 중에서 피자식물의 유연관계에 유용한 코딩 지역의 $m a t \mathrm{~K}$ 를 이용하였다. $m a t \mathrm{~K}$ 의 분석 결과 금붓
꽃 complex의 경우 완전한 단계통군을 이루고 있으며, 잡 종추정군을 제외한 세 분류군에서 종간의 염기서열 차이 가 분명하게 나타나 종간 유연관계 분석이 용이하였다. 이전 Lee (2013)의 cpDNA 논코딩 지역인 $p s b \mathrm{~A}-t r n \mathrm{H}$ 와 $t r n \mathrm{~L}-\mathrm{F}$ 지역의 분석에서는 노랑무늬붓꽃과 노랑붓꽃+금 붓꽃는 해결하였으나, 노랑붓꽃과 금붓꽃의 경우 독립된 분계조를 형성하지 못해 유전적 특성의 관계를 해결하지 못하였다. 하지만 코딩지역인 $m a t K$ 의 결과 이전 ITS와 논 코딩지역으로도 해결하지 못한 두 종의 관계를 하나의 염 기서열로 차이를 보이며 NJ 계통수에서 해결할 수 있었다. 팔공산에서 발견한 잡종추정군의 경우 같은 서식처를 공 유하는 금붓꽃 뿐만 아니라 다른 지역의 금붓꽃 개체군들 과 모두 같은 염기서열을 보이며 $100 \%$ 의 높은 지지율로 하나의 분계조를 형성하였다. 이로써 잡종추정군의 경우 모계는 금붓꽃으로 추측된다.

ITS는 양친유전을 하며 다른 코딩 지역보다 더 빠르게 진화하여 유전자간의 변이성이 높은 편으로 종간 또는 속 간의 유연관계와 진화경향성 및 유전변이양상을 파악하 는 데 중요한 자료로 이용되었다(Kim et al., 2014). 또한 여 러 종간잡종을 파악하는 데 있어 사용되는 유용한 마커이 다(Son et al., 2009; Shin et al., 2014). 본 실험의 금붓꽃 complex의 세 분류군의 경우 한 개체 내에서 매우 높은 다 형성을 보였다. nrDNA의 ITS지역은 rRNA (ribosomal RNA)의 사이에 있는 지역으로 수천 개의 동일 단위가 반 복되어 존재하는 특징을 가지고 있으며, 이러한 많은 동 일 단위들은 각각 독립적으로 진화하지 않고, 서로 유전 적 상호작용에 의하여 동일한 염기서열을 유지하면서 다 같이 수렴을 이루어서 진화하는 것으로 알려져 있다 (Arnheim, 1983). 하지만, 불완전한 수렴이 여러 번의 반복 에 걸쳐 일어난 경우, 다형성의 형태인 multiple divergent ITS paralogue가 일어난다. 이는 Corymbia속, 배나무속 (Pyrus) 그리고 소철속(Cycas) 등 여러 분류군에서 관찰된 바 있다(Ochieng et al., 2007; Zheng et al., 2008, Xiao et al., 2009). 또한 nrDNA paralogue는 잡종을 포함하거나 유전체 내의 비상동 염색체에 분산되어 있는 paralogue 사이에서 수렴진화가 불완전한 경우 개체 내에서도 다형성이 발생 한다고 보고된 바 있다(Bailey et al., 2003; Xiao et al,. 2010). 이러한 원인에 의해 Iris 속 내에서도 ITS의 다형현상이 나 타났을 것으로 생각된다.

ITS NJ 계통수는 전체적으로 cpDNA matK 계통수보다 해상도가 낮아 유연관계를 파악하는 데 부적합하였으나, 군외군인 각시붓꽃 complex와 높은 $\mathrm{BS}$ 값으로 자매군을 형성하였다는 점과 금붓꽃 complex 세 분류군과 잡종추정 군이 단계통임을 지지하고 있어 집단 간 유연관계 파악에 는 도움을 줄 수 있다고 사료된다. 또한 종간 유연관계에 서는 노랑붓꽃과 금붓꽃의 경우 많은 다형성을 보이고 있 으며 관계를 명확히 해결하지 못했으나, 노랑무늬붓꽃의 경우 높은 $\mathrm{BS}$ 값으로 하나의 분계조를 지지함으로써 종간 
에 차이를 보인다. ITS 계통수에서 잡종추정군의 일부는 노랑무늬붓꽃과 하나의 분계조를 나타내고, 나머지 잡종 추정군의 경우는 금붓꽃+노랑붓꽃의 분계조에 포함됨으 로써 팔공산 가산에서 나타나는 잡종추정군의 부계는 노 랑무늬붓꽃이라는 가능성을 제시하고 있다.

\section{사 사}

본 연구는 국립수목원 '희귀 · 특산식물 보존 및 복원 인 프라 구축 (KNA1-2-10, 10-1)' 연구개발사업의 지원으로 수행되었습니다.

\section{Literature Cited}

Arnheim, N. 1983. Concerted evolution of multigene families. In M. Nei and R.K. Koehn (eds.), Evolution of Genes and Proteins. pp. 38-61.

Arnold M. L., B. D. Bennett and E. A. Zimmer. 1990. Natural hybridization between Iris fulva and Iris hexagona: pattern of ribosomal DNA variation. Evolution 44(6): 1512-1521.

Bailey, C. D., T. G. Carr, S. A. Harris and C. E. Hughes. 2003. Characterization of angiosperm nrDNA polymorphism, paralogy and psedogenes. Molecular Phylogenetics and Evolution 29: 435-455.

CBOL Plant Working Group. 2009. A DNA barcode for land plants. Proceedings of the National Academy of Sciences 106: 12794-12797.

Dong, W., J. Liu, J. Yu, L. Wang and S. Zhou. 2012. Highly variable chloroplast markers for evaluating plant phylogeny at low taxonomic levels and for DNA barcoding. PloS ONE 7(4): e35071.

Doyle, J. J. and J. A. Doyle. 1987. A rapid DNA isolation procedure for quantities of fresh leaf tissue. Phytochemical Bulletin. 19: 11-15.

Drummond, A. J., B. Ashton, S. Buxton, M. Cheung, A. Cooper, C. Duran, M. Field, J. Heled, M. Kearse, S. Markowitz, R. Moir, S. Stones-Havas, S. Sturrock, T. Thierer and A. Wilson. 2011. Geneious v6.1. from http://www.geneious.com

Felsenstein, J. 1985. Confidence limits on phylogenies: an approach using the bootstrap. Evolution 39: 783-791.

Hong, J. R. 2012. DNA sequence based species identification of Asparagales and Liliales for the Korea flora. M.S. thesis, Korea University, Korea.

Kim, Y. K., S. J. Jo and K. J. Kim. 2014. Phylogenetic position of Neofinetia and Sedirea (Orchidaceae) and their species identification using the chloroplast matK and the nuclear ITS sequences. Korean Journal of Plant Taxonomy 44(1): 39-50.

Korea National Arboretum. 2008. Rare plants Data Book in
Korea. Korea National Arboretum, Pocheon. (in Korean)

Lee, H. J. and S. J. Park. 2013. A phylogenetic study of Korean Iris L. based on plastid DNA ( $p s b \mathrm{~A}-t r n \mathrm{H}$, $\operatorname{trn} \mathrm{L}-\mathrm{F}$ ) sequences. Korean Journal of Plant Taxonomy 43(3): 227-235.

Lee, T. B. 1976. Bulletin of the Kwanak Arboretum (1). Pp. 128 129. (in Korean)

Lee, T. B. 1979. Illustrated Flora of Korea. Hyangmunsa, Seoul. Pp. 247-248. (in Korean)

Lee, T. B. 1984. Outline of Korean endemic plants and their distribution. Korean Journal of Plant Taxonomy 14: 21-32. (in Korean)

Lee, W. T. and W. H. Lee. 1964. Report on study of a new forma of Iridaceae plants. Seoul Agricultural College: 1-4.

Lee, Y. N. 1974. New taxa on Korean flora (1). Korean Journal of Plant Taxonomy 17: 33-35.

Lee, Y. N. 1996. Flora of Korea. Kyohak Publishing Co., Seoul. Pp. 951-956. (in Korean)

Loockerman, D. J. and R. K. Jansen. 1996. The use of herbarium material for DNA studies. In sampling the green world. Stussey, T. J. and S. Sohmer (eds.), Columbia University Press, New York, USA. Pp. 205-220.

Mori, T. 1921. An enumeration of plants hitherto known from Korea. The Government of Chosen, Seoul.

Nakai, T. 1911. Flora koreana. Journal College Science Important. University Tokyo. 31: 230-234. (in Japanese)

Nakai, T. 1914. Report in the vegetation of Quelpart and Wanto Island. The Government of Chosen, Seoul. Pp. 1-156. (in Japanese)

Nakai, T. 1952. A Synoptical Sketch of Korean Flora. Bulletin of the National Science Museum, Tokyo. P. 148.

Ochieng, J. W., R. J. Henry, P. R. Baverstock, D. A. Steane and M. Shepherd. 2007. Nuclear ribosomal pseudogenes resolve a corroborated monophyly of the eucalypt genus Corymbia despite misleading hypotheses at functional ITS paralogs. Molecular Phylogenetics and Evolution 44: 752-764.

Oh, S. Y. 1986. The Enumerative and Phytogeographical Studies of Family Iridaceae in Korea. Research Review of Kyungpook National University. 42: 193-234.

Palibin, J. W. 1901. Conspectus florae Korea . Acta Horti Petropolitani 19: 106-108.

Shin, H. C., S. H. Oh, Y. S. Lim, C. W. Hyun, S. H. Cho, Y. I. Kim and Y. D. Kim. 2014. Molecular evidence for hybrid origin of Aster chusanensis, an Endemic species of Ulleungdo, Korea. Journal of Plant Biology 57: 174-185.

Sim, J. K. 1988. A taxonomic study on Iridaceae in Korea. Ph. D. thesis, Korea University, Korea. (in Korean)

Sim, J. K. 1992. New taxa of Iridaceae from Korea. Korean Journal of Plant Taxonomy 22(1): 1-5. (in Korean) 
Sim, J. K. and J. H. Kim. 2002. A systematic study of the genus Iris series Chinensis Lawrene (Iridaceae) based on RAPD analysis. Korean Journal of Plant Taxonomy 32(1): 95-108. (in Korean)

Sim, J. K., H. D. Park and S. J. Park. 2002. Phylogenetic study of Korean Iris (Iridaceae) based on nrDNA ITS sequences. Korean Journal of Plant Taxonomy 32(1): 33-53. (in Korean)

Son, S. W., J. H. Kim, K. J. Kim and S. J. Park. 2009. Molecular evidence for the hybridity of Ilex $\times$ wandoensis and the phylogenetic study of Korean Ilex based on ITS sequence data. Gene and Genomics 31(1): 53-63.

White, T. J., T. Bruns, S. Lee and J. Taylor. 1990. Amplification and direct sequencing of fungal ribosomal RNA genes for phylogenetics. In PCR Protocols: A guide to methods and applications, Innis, M. A., D. H. Gelfand, J.J. Sninsky and T. J. White (eds.), Academic Press, San Diego. Pp. 315-322.

Wolf, P. G., K. M. Pryer, A. R. Smith and M. Hasebe. 1998. Phylogenetic studies of extant pteridophytes. In: Molecular Systematics of Plant, Second Edition. P. S. Soltis, D. E. Soltis., J. J. Doyle (Eds.) Chapman and Hall. 541-556.
Xiao, L. Q., M. Moller and H. Zhu. 2010. High nrDNA ITS polymorphism in the ancient extant seed plant Cycas: incomplete concerted evolution and the origin of pseudogenes. Molecular Phylogenetics and Evolution 55: 168-177.

Young N. D. 1996. Concordance and discordance: a tale of two hybrid zones in the pacific coast irises (Iridaceae). American Journal of Botany 83(12): 1623-1629.

Yu, J., J. H. Xue and S. L. Zhou. 2011. New universal matK primers for DNA barcoding angiosperms. Journal of Systematics and Evolution 49(3): 176-181.

Yu, Z. Y. 2009. Karyotype studies on ten Iris species (Iridaceae) from Sichuan, China. 62(3): 253-260.

Zhao, Y., H. J. Noltie and B. Mathew. 2000. Iridaceae. In Flora of China Vol. 24. Wu, Z. Y., P. H. Raven and D. Y. Hong (eds), Science Press, Beijing, and Missouri Botanical Garden Press, St. Louis. Pp 297-313.

Zheng, X. Y., D. Y. Cai, L. H. Yao and Y. W. Teng. 2008. Nonconcerted ITS evolution, early origin and phylogenetic utility of ITS pseudogenes in Pyrus. Molecular Phylogenetics and Evolution 48: 892-903. 